\title{
Adsorption kinetics, isotherms and thermodynamics of atrazine on surface oxidized multiwalled carbon nanotubes
}

\author{
Guang-Cai Chen ${ }^{\mathrm{a}, \mathrm{b}}$, Xiao-Quan Shan ${ }^{\mathrm{a}, *}$, Yi-Quan Zhou ${ }^{\mathrm{b}}$, Xiu-e Shen ${ }^{\mathrm{a}}$, \\ Hong-Lin Huang a , Shahamat U. Khan ${ }^{c}$ \\ a State Key Laboratory of Environmental Chemistry and Ecotoxicology, Research Center for Eco-Environmental Sciences, \\ Chinese Academy of Sciences, PO Box 2871, Beijing 100085, China \\ ${ }^{\mathrm{b}}$ Research Institute of Subtropical Forestry, Chinese Academy of Forestry, Fuyang, Zhejiang Province 311400, China \\ ${ }^{c}$ Department of Chemistry and Biochemistry, MSN 3E2, George Mason University, 4400 University Drive, Fairfax, VA 22030-4444, USA
}

\section{A R T I C L E I N F O}

\section{Article history:}

Received 12 September 2008

Received in revised form 9 April 2009

Accepted 9 April 2009

Available online 18 April 2009

\section{Keywords:}

Adsorption

Atrazine

Carbon nanotubes

Kinetics

Thermodynamics

\begin{abstract}
A B S T R A C T
The adsorption kinetics, isotherms and thermodynamic of atrazine on multiwalled carbon nanotubes (MWCNTs) containing $0.85 \%, 2.16 \%$, and $7.07 \%$ oxygen was studied. Kinetic analyses were performed using pseudo-first-order, pseudo-second-order and intraparticle diffusion models. The regression results showed that the pseudo-second-order law fit the adsorption kinetics. The calculated thermodynamic parameters indicated that adsorption of atrazine on MWCNTs was spontaneous and exothermic. Standard free energy $\left(\Delta G^{0}\right.$ ) became less negative when the oxygen content of MWCNTs increased from $0.85 \%$ to $7.07 \%$ which is consistent with the low adsorption affinity of MWCNTs for atrazine.
\end{abstract}

(c) 2009 Elsevier B.V. All rights reserved.

\section{Introduction}

Atrazine [2-chloro-4-ethylamino-6-isopropylamino-s-triazine] has been widely used as a pre- and post-emergent herbicide to control broad leaf weeds in field crops, orchards and non-cropped areas [1]. Due to its widespread use, long-term persistence in soil, greater leaching potential and relatively high solubility in water, atrazine is frequently detected in ground, surface and drinking waters [2,3]. Although atrazine is toxic to animals [4] and humans [5] and its use has been banned in European Union countries since 2003 [6], this chlorotriazine herbicide still remains in use in China. While the European Union legislation allows a very low concentration of atrazine in drinking water $(0.1 \mathrm{ppb})$, this limit is set to $3 \mathrm{ppb}$ in China [6,7]. Atrazine contamination of surface and subsurface waters has heightened public concern over its environmental impact. Recently, atrazine is recognized as an endocrine disruptor for mammals [8] and aquatic life [9]. The sorption and desorption processes play an important role in determining the fate of atrazine in the environment. Despite the extensive information available on atrazine adsorption on and desorption from soil, activated carbon and minerals [10-12], very little is known

\footnotetext{
* Corresponding author. Tel.: +86 10 62923560; fax: +861062923563.

E-mail addresses: xiaoquan@rcees.ac.cn, xq_shan1@yahoo.com (X.-Q.Shan).
}

about the adsorption of atrazine onto surface modified carbon nanotubes.

Depending on the layers involved carbon nanotubes (CNTs) have been referred to singlewalled (SWCNTs) or multiwalled carbon nanotubes (MWCNTs). CNTs have been considered useful in pollution prevention strategies and are known to have widespread applications as environmental adsorbents and high flux membranes [13], and are also potentially important for in situ environmental remediation due to their unique properties and high reactivity [14]. Investigations dealing with the sorption of organic contaminants, such as dioxin [15], 1,2-dichlorobenzene [16], trihalomethanes [17], PAHs [18] and $o$-xylene, $p$-xylene [19] and reactive dyes [20] on CNTs suggest that CNTs may also be suitable candidates for the pre-concentration and solidification of pollutants from large volumes of wastewater. Strong adsorptive interaction between CNTs and polycyclic aromatic hydrocarbons were ascribed to $\pi-\pi$ electron-donor-acceptor (EDA) interactions between aromatic molecules (electron acceptors) and the highly polarizable graphene sheets (electron donors) of CNTs [18,21]. In addition, hydrophobic effect, dispersion and weak dipolar forces as well as micropore diffusion are also considered to be responsible for adsorption [18,19,22].

The adsorption of organic contaminants on MWCNTs has been studied extensively [14-22]. The adsorption of atrazine on MWCNTs was reported by Yan et al. [23] and Chen et al. [24]. They found 
Table 1

Selected structural properties of MWCNTs.

\begin{tabular}{|c|c|c|c|c|c|c|c|}
\hline Carbons & $\begin{array}{l}\text { Outer diameter } \\
(\mathrm{nm})\end{array}$ & $\begin{array}{l}\text { Inner diameter } \\
(\mathrm{nm})\end{array}$ & $\begin{array}{l}\text { Carbon content } \\
(\%)\end{array}$ & $\begin{array}{l}\text { Oxygen content } \\
\text { atom }(\%)\end{array}$ & $\begin{array}{l}\text { Surface area } \\
\left(\mathrm{m}^{2} \mathrm{~g}^{-1}\right)\end{array}$ & $\begin{array}{l}\text { Mesopore volume } \\
\left(\mathrm{cm}^{3} \mathrm{~g}^{-1}\right)\end{array}$ & $\begin{array}{l}\text { Micropore volume } \\
\left(\mathrm{cm}^{3} \mathrm{~g}^{-1}\right)\end{array}$ \\
\hline MWCNTs-O (0.85\%) & $10-20$ & $5-10$ & 99 & 0.85 & 167 & 0.619 & 0.016 \\
\hline MWCNTs-O (2.16\%) & $10-20$ & $5-10$ & 97 & 2.16 & 178 & 0.629 & 0.015 \\
\hline MWCNTs-O (7.07\%) & $10-20$ & $5-10$ & 92 & 7.07 & 185 & 0.756 & 0.024 \\
\hline
\end{tabular}

that the adsorption of atrazine was exothermic and diminished by $\mathrm{Cu}^{2+}, \mathrm{Pb}^{2+}$ and $\mathrm{Cd}^{2+}$. However, very little is known about the kinetic of atrazine adsorption on the surface oxidized MWCNTs. Understanding of adsorption kinetics, thermodynamics and equilibrium is also critical for the design and operation of adsorption equipment.

In view of the foregoing the objective of this study was to investigate atrazine adsorption kinetic, thermodynamics and isotherms on oxidized MWCNTs. The adsorption rates were evaluated with the pseudo-first-order, pseudo-second-order and intraparticle diffusion model and Polanyi-Manes equation. The effects of temperature on the adsorption isotherms were determined and the thermodynamic parameters of the changes of free energy $\left(\Delta G^{0}\right)$, enthalpy $\left(\Delta H^{0}\right)$ and entropy $\left(\Delta S^{0}\right)$ during adsorption at various temperatures were calculated.

\section{Materials and methods}

\subsection{Materials}

Atrazine (97.4\% purity) was purchased from Sigma-Aldrich Chemical Co. and used directly without further purification. Atrazine has a $\log K_{o w}$ of $2.74, \log K_{o c}$ of $1.95-2.71$, water solubility of $28 \mathrm{mg} \mathrm{L}^{-1}\left(20^{\circ} \mathrm{C}\right)$ and $\mathrm{p} K_{\mathrm{a}}$ of 1.7 [25]. All other chemicals used in this study were of analytical reagent grade or better.

MWCNTs were purchased from Chengdu Organic Chemistry Co. Ltd., Chinese Academy of Sciences. The MWCNTs were synthesized from the $\mathrm{CH}_{4} / \mathrm{H}_{2}$ mixture by chemical vapor deposition method at $700^{\circ} \mathrm{C}$ using Ni particles as a catalyst. The MWCNTs with outer diameters of $10-20 \mathrm{~nm}$ and designated as MWCNTs-O $(0.85 \%)$, MWCNTs-O (2.16\%) and MWCNTs-O (7.07\%) had surface area of 167, 185 and $178 \mathrm{~m}^{2} \mathrm{~g}^{-1}$, and surface oxygen contents of $0.85 \%, 2.16 \%$ and $7.07 \%$, respectively. Preliminary experiments indicated that MWCNTs were free of any residual native (or post-production adsorbed) atrazine.

\subsection{Characterization of MWCNTs}

The surface area and pore volume were measured by nitrogen gas adsorption and desorption at $77 \mathrm{~K}$ with ASAP2000 (Micromeritics Instrument Corporation). They were calculated by multi-point $\mathrm{BET}, \mathrm{BJH}$, and DR methods. The micropore volume was measured by carbon dioxide sorption with Quantachrome instruments v2.2 and calculated with DFT method. The oxygen content was determined by X-ray photoelectron spectroscopy (ESCALab220i$\mathrm{XL}$ electron spectrometer from VG Scientific) using $300 \mathrm{~W} \mathrm{Al}$ $\mathrm{K} \alpha$ radiation under the base pressure about $3 \times 10^{-9}$ mbar. The structural properties of MWCNTs are shown in Table 1 . The Raman measurements (Renishaw RM2000) of MWCNTs were carried out at room temperature using a $632.8 \mathrm{~nm}$ output from a $\mathrm{He}-\mathrm{Ne}$ laser as the excitation wavelength in backer scattering configuration. The functional groups on the surface of MWCNTs were determined by a Fourier transform infrared (FTIR) spectroscopy equipped with deuterated triglycine (DTGS) and mercury-cadmium-telluride (MCT) detectors (NEXUS 670 FTIR, Nicolet).

\subsection{Sorption kinetics}

The sorption kinetics experiments were performed in $40 \mathrm{~mL}$ glass centrifuge tubes sealed with Teflon-lined screw-caps. Five milligrams of MWCNTs were introduced to $25 \mathrm{~mL}$ of $0.01 \mathrm{M} \mathrm{NaNO}_{3}$ and $0.1 \mathrm{~g} \mathrm{~L}^{-1} \mathrm{NaN}_{3}$ with the initial atrazine concentration of $4.2 \mathrm{mg} \mathrm{L}^{-1}$. The suspensions were shaken at $100 \mathrm{rpm}$ for certain time intervals at $\mathrm{pH} 6 \pm 0.1$ by dropwise addition of $0.1 \mathrm{M}$ $\mathrm{HNO}_{3}$ or $0.1 \mathrm{M} \mathrm{NaOH}$ in a shaker (HZQ-F160, Beijing, China) at $293.5 \pm 0.5 \mathrm{~K}$. The supernatant were filtered through a $0.45 \mu \mathrm{m}$ cellulose acetate membrane filter, and analyzed. The quantity of atrazine adsorbed at time $t, q_{t}\left[\mathrm{mg} \mathrm{g}^{-1}\right]$, was deduced from the mass balance between initial concentration and concentration at time $t$ in solution.

\subsection{Sorption isotherms}

A batch technique was utilized for all sorption experiments with $5 \mathrm{mg}$ MWCNTs and $25 \mathrm{~mL}$ of background solution of 0.01 or $0.1 \mathrm{M} \mathrm{NaNO}_{3}$ in deionized water containing $0.1 \mathrm{~g} \mathrm{~L}^{-1} \mathrm{NaN}_{3}$ as a biocide in $40 \mathrm{~mL}$ of glass vials sealed with Teflon-lined screw-caps. Reactors were filled with MWCNTs and initial aqueous solution were mixed completely by shaking at $100 \mathrm{rpm}$ at a given temperature $(288.5 \pm 0.5,298.5 \pm 0.5$ or $308.5 \pm 0.5 \mathrm{~K})$ in a shaker for 2 days. The $\mathrm{pH}$ value of the background solution containing $1-8 \mathrm{mg} \mathrm{L}^{-1}$ atrazine varied from 6 to 7 . The suspensions were adjusted by dropwise addition of $0.1 \mathrm{M} \mathrm{HNO}_{3}$ or $0.1 \mathrm{M} \mathrm{NaOH}$ to $\mathrm{pH} 6$ at the beginning of adsorption in order to eliminate the influence of different $\mathrm{pH}$ on the adsorption. The preliminary experimental results showed that the $\mathrm{pH}$ of the equilibration suspensions remained unchanged during the adsorption processes. After centrifugation at $2000 \times \mathrm{g}$ for $20 \mathrm{~min}$ under controlled temperature, the supernatants were sampled, and analyzed. Blank experiments were performed using the same procedure but without MWCNTs in order to check the potential sorption of atrazine to the glass centrifuge tubes or the membrane filters. Prelimi-

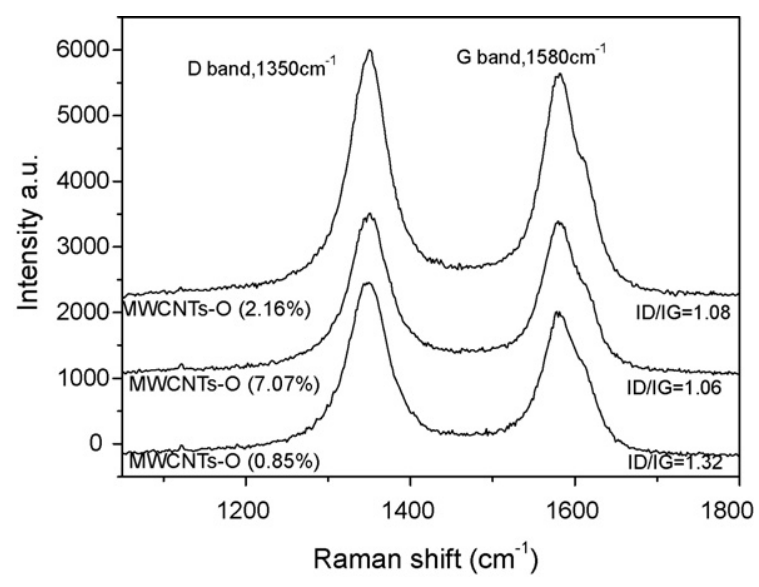

Fig. 1. Raman spectra of MWCNTs. 


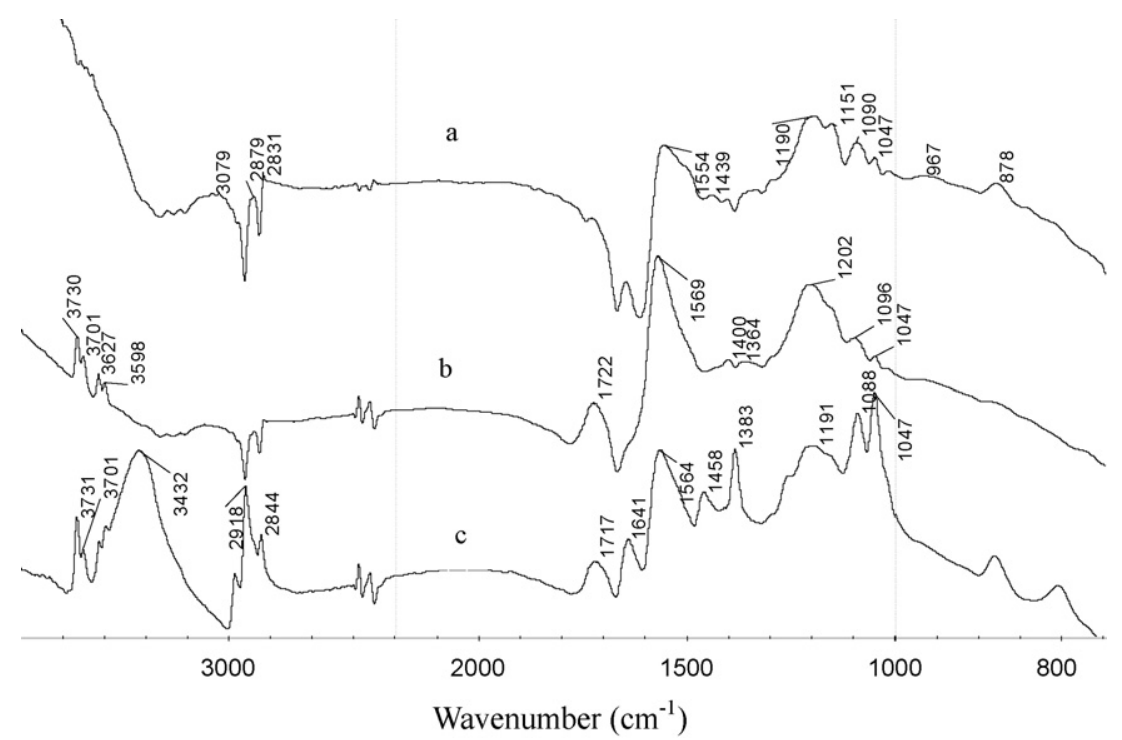

Fig. 2. FTIR spectra of MWCNTs: (a) MWCNTs-O (0.85\%), (b) MWCNTs-O (2.16\%), and (c) MWCNTs-O (7.07\%).

nary experimental results indicated that such losses were $<3 \%$ of the initial concentrations of atrazine. Therefore the adsorbed amounts of atrazine by MWCNTs were directly calculated from mass differences between the initial and final equilibrium concentrations.

\subsection{Analysis}

Atrazine in supernatant was determined by high performance liquid chromatograph (HPLC, Agilent 1200) equipped with an autoinjector and photodiode array UV-vis absorption detector and an extended polar selectivity reversed-phase column $(15 \mathrm{~cm} \times 4.6 \mathrm{~mm}$ i.d.). The absorption wavelength was $222 \mathrm{~nm}$. The mobile phase was $60 / 40$ (volume ratio) methanol/water, and the flow rate was $0.7 \mathrm{~mL} \mathrm{~min}^{-1}$. Concentrations of pesticide adsorbed on MWCNTs versus those in aqueous solution were used to construct isotherms with the adsorbed mass calculated by the difference between the initial and the equilibrium solute concentration in aqueous solution.

\section{Results and discussion}

\subsection{Characterizations of MWCNTS}

The Raman spectra of MWCNTs shown in Fig. 1 are composed of two characteristic peaks for the nanotubes. The $G$ band near $1580 \mathrm{~cm}^{-1}$ is related to the graphite $E_{2 g}$ symmetry of the interlayer mode, which reflects the structural intensity of the $\mathrm{sp}^{2}$ hybridized carbon atoms of the nanotubes. The D band at $1350 \mathrm{~cm}^{-1}$ is due to defected sites in the hexagonal framework of carbon nanotube walls, and will be enhanced by chemical modification on the sidewalls [26]. The extent of defect in carbon nanotubes can be evaluated with a ratio of intensity of D band to $G$ band (ID/IG). In Fig. 2, the ID/IG ratio is in descending order MWCNTs-O $(0.85 \%)>$ MWCNTs-O $(2.16 \%)>$ MWCNTs-O $(7.07 \%)$ thereby indicating that the surface properties of MWCNTs were improved after oxidation $[27,28]$.

The $\mathrm{N}_{2}$ adsorption and desorption isotherms for the specific surface area measurement present a type IV nitrogen adsorption

Table 2

Coefficients of kinetic model regression (atrazine concentration of $4.2 \mathrm{mg} \mathrm{L}^{-1}, \mathrm{pH} 6$ ).

\begin{tabular}{|c|c|c|c|c|c|}
\hline Pseudo-first-order model & $q_{e, \text { measured }}\left(\mathrm{mg} \mathrm{g}^{-1}\right)$ & $k_{1}\left(\mathrm{~h}^{-1}\right)$ & $q_{e, \text { calculated }}\left(\mathrm{mg} \mathrm{g}^{-1}\right)$ & $R^{2}$ & S.D. (\%) \\
\hline \multicolumn{6}{|l|}{ Carbon } \\
\hline MWCNTs-O (0.85\%) & 17.35 & 0.8757 & 9.37 & 0.993 & 25.56 \\
\hline MWCNTs-O (2.16\%) & 16.65 & 0.4732 & 3.06 & 0.993 & 51.34 \\
\hline MWCNTs-O (7.07\%) & 10.50 & 0.4415 & 3.22 & 0.930 & 45.36 \\
\hline Pseudo-second-order model & $q_{e, \text { measured }}\left(\mathrm{mg} \mathrm{g}^{-1}\right)$ & $k_{2}\left(\mathrm{~h}^{-1}\right)$ & $q_{e, \text { calculated }}\left(\mathrm{mg} \mathrm{g}^{-1}\right)$ & $R^{2}$ & S.D. (\%) \\
\hline \multicolumn{6}{|l|}{ Carbon } \\
\hline MWCNTs-O (0.85\%) & 17.35 & 0.925 & 17.283 & 1 & 6.53 \\
\hline MWCNTs-O (2.16\%) & 16.65 & 0.635 & 16.697 & 1 & 0.52 \\
\hline MWCNTs-O (7.07\%) & 10.50 & 1.178 & 10.408 & 1 & 0.79 \\
\hline Intraparticle diffusion model & $k_{i}\left(\mathrm{mg} \mathrm{g}^{-1}\right.$ & & $c\left(\mathrm{mgg}^{-1}\right)$ & $R^{2}$ & S.D. (\%) \\
\hline \multicolumn{6}{|l|}{ Carbon } \\
\hline MWCNTs-O (0.85\%) & 5.551 & & 7.011 & 0.955 & 0.34 \\
\hline MWCNTs-O (2.16\%) & 1.633 & & 13.11 & 0.982 & 0.03 \\
\hline MWCNTs-O (7.07\%) & 1.862 & & 6.378 & 0.955 & 0.32 \\
\hline
\end{tabular}

S.D. mean standard deviation, equal to $\left(\sqrt{\left(\sum\left(q_{e, \text { measured }}-q_{e, \text { calculated }}\right)^{2}\right) /(n-1)}\right) \times 100$, where $n$ is the number of data points. 
isotherm with a hysteresis loop. This is typical of a mesoporous material where desorption requires definitively higher energy than adsorption according to the IUPAC classification (data not shown) [29]. In all cases due to a capillary condensation, a considerable increase of the adsorption of $\mathrm{N}_{2}$ occurred above $P / P_{0}=0.8$. Hysteresis loop was observed with RP above 0.8 for the three MWCNTs.

The FTIR spectra of MWCNTs were obtained in $\mathrm{KBr}$ pellet $(0.2 \%)$ and resolution of $4 \mathrm{~cm}^{-1}$ at $21 \mathrm{scans}^{\mathrm{min}}{ }^{-1}$ are expressed in transmittance in $3800-700 \mathrm{~cm}^{-1}$ range (Fig. 2). The important absorption bands at frequency values that justify the existence of the corresponding functional groups (bonds) were: $\mathrm{O}-\mathrm{H}$ ( $3598 \mathrm{~cm}^{-1}$ in Fig. 2b, and $3432 \mathrm{~cm}^{-1}$ in Fig. 2 c; stretch vibration), $\mathrm{C}=\mathrm{O}\left(1722 \mathrm{~cm}^{-1}\right.$ in Fig. $2 \mathrm{~b}$ and $1717 \mathrm{~cm}^{-1}$ in Fig. $2 \mathrm{c}$, stretch vibration), and $\mathrm{C}-\mathrm{O}\left(1202,1096\right.$, and $1047 \mathrm{~cm}^{-1}$ in Fig. 2b, and 1088 and $1047 \mathrm{~cm}^{-1}$ in Fig. 2c; stretch vibration). These functional groups are hydrophilic thus making the CNTs disperse in water more easily.

\subsection{Adsorption kinetics}

Adsorption kinetic is one of the most important characters which govern the solute uptake rate and represents the adsorption efficiency of the adsorbent and therefore, determines its potential applications. According to Fig. 3, atrazine adsorption rates increased dramatically in the first $1 \mathrm{~h}$, and reached apparent equilibrium gradually within $3 \mathrm{~h}$. The amount of adsorbed atrazine by MWCNTs-O (0.85\%), MWCNTs-O (2.16\%) and MWCNTs-O (7.07\%) was found to be $17.35,16.65$ and $10.50 \mathrm{mg} \mathrm{g}^{-1}$, respectively (Table 2). Since MWCNTs have no porous structure-like activated carbon, the adsorbate will likely move from the exterior surface to the inner surface of the pores on adsorbents to achieve equilibrium [16]. To analyze the adsorption rate of atrazine onto different MWCNTs, the pseudofirst-order Eq. (1) and second-order models Eq. (2) [30,31] were evaluated based on the experimental data:

$\ln \left(q_{e}-q_{t}\right)=\ln q_{e}-k_{1} t$

$\frac{t}{q_{t}}=\frac{1}{k_{2} q_{e}^{2}}+\frac{1}{q_{e}} t$

where $q_{e}\left[\mathrm{mg} \mathrm{g}^{-1}\right]$ and $q_{t}\left[\mathrm{mg} \mathrm{g}^{-1}\right]$ are the concentrations of atrazine adsorbed on MWCNTs at equilibrium and at various time $t, k_{1}\left[\mathrm{~h}^{-1}\right]$ is the rate constant of Eq. (1) for the adsorption, $k_{2}\left[\mathrm{~g} \mathrm{mg}^{-1} \mathrm{~h}^{-1}\right]$ is the rate constant of Eq. (2) for adsorption. The values of $q_{e}$ and $k_{1}$ can be calculated from the intercept and the slope of the linear plot of $\ln \left(q_{e}-q_{t}\right)$ versus $t$ for Eq. (1). Furthermore, the slope and intercept of the linear plot of $t / q$ against $t$ yielded the values of $1 / q_{e}$ and $1 / k_{2} q_{e}^{2}$ for Eq. (2).

The linear regression of sorption kinetics is shown in Fig. 4a and b and Table 2. The $R^{2}$ value of Eq. (2) is near 1 which is larger than that

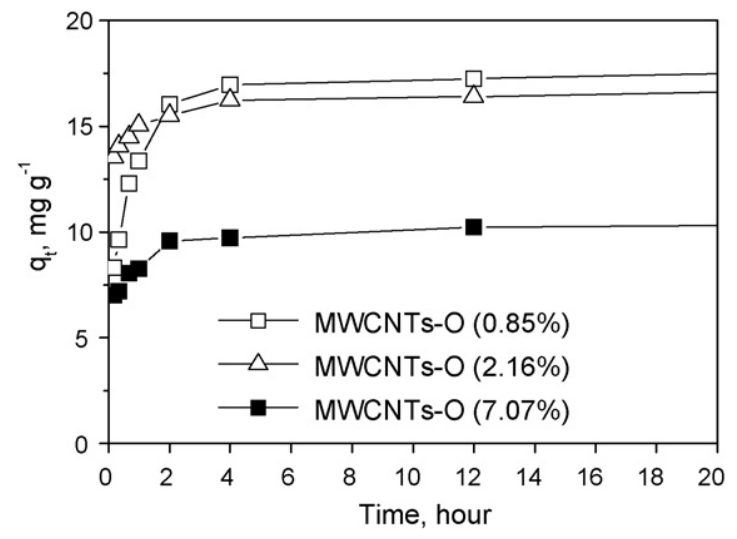

Fig. 3. Sorption kinetics of atrazine on MWCNTs.
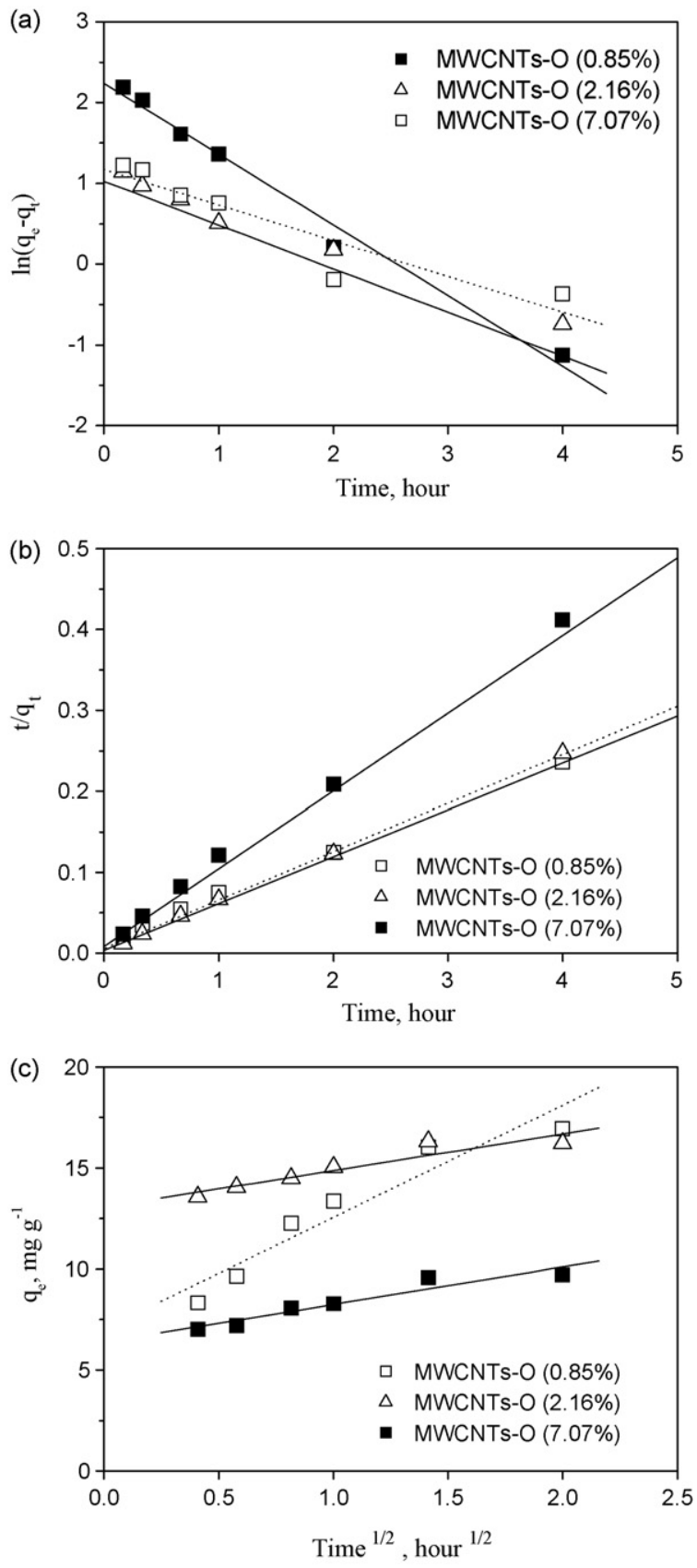

Fig. 4. Linear regressions of kinetics plot: (a) pseudo-first-order model, (b) pseudosecond-order model, and (c) intraparticle diffusion model.

of Eq. (1), and the standard deviations of Eq. (2) were significantly smaller than those of Eq. (1). Moreover, the $q_{e \text {, measured }}$ values were

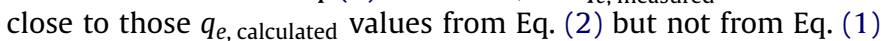
(Table 2). In general our data indicates that the adsorption kinetics of atrazine by MWCNTs can be better described in Eq. (2).

Generally, intraparticle diffusion mechanism is one of the most limiting factors which control the adsorption kinetics [32]. Hence, the intraparticle diffusion model was utilized to determine the ratelimiting step of the adsorption process:

$q_{t}=k_{i} t^{1 / 2}+c$

where $c\left[\mathrm{mg} \mathrm{g}^{-1} \mathrm{~h}^{1 / 2}\right]$ is the intercept and $k_{i}$ is the intraparticle diffusion rate constant, which can be evaluated from the slope of the linear plot of $q_{t}$ versus $t^{1 / 2}$ [33]. If the regression of $q_{t}$ versus $t^{1 / 2}$ is linear and passes through the origin, then intraparticle diffusion is 


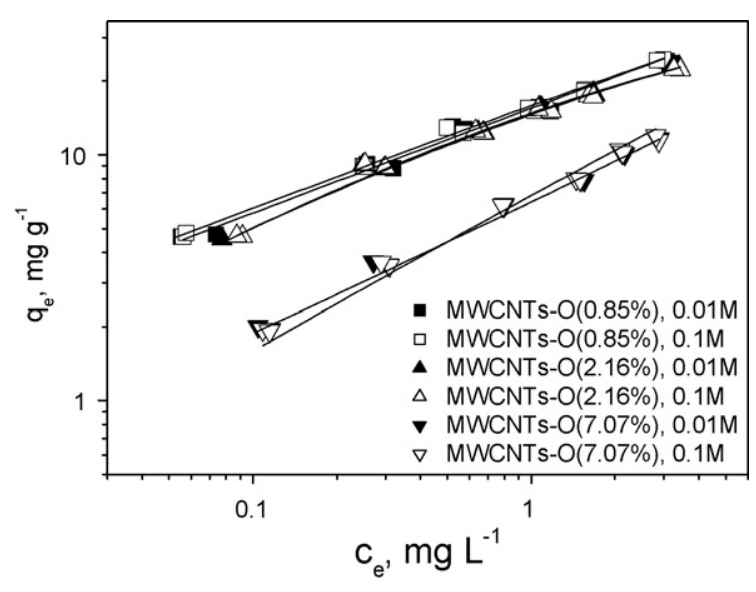

Fig. 5. Sorption isotherms of atrazine adsorption onto MWCNTs at $298 \mathrm{~K}$ with ion strength of 0.01 and $0.1 \mathrm{M} \mathrm{NaNO}_{3}$, respectively, and PMM fittings.

the sole rate-limiting step [34,35]. In our study although the regression was linear, the plot did not pass through the origin (Fig. 4c) thereby suggesting that intraparticle diffusion was related to the adsorption but not as a sole rate-controlling step.

\subsection{Sorption isotherms}

The sorption isotherms of atrazine at different ionic strength at temperature of $298.5 \mathrm{~K}$ are shown in Fig. 5. The results also show that the ionic strength has little effect on the sorption of atrazine by MWCNTs. The experimental data fit well by Polanyi-Manes models (PMM):

$q_{e}=Q^{0} \exp a\left(\frac{\varepsilon_{s w}}{V_{s}}\right)^{b}$

$\varepsilon_{s w}=R T \ln \left(\frac{C_{s}}{C_{e}}\right)$

where $Q^{0}\left[\mathrm{mg} \mathrm{g}^{-1}\right]$ is adsorption capacity, $\varepsilon_{s w}\left[\mathrm{~kJ} \mathrm{~mol}^{-1}\right]$ is the effective adsorption potential; $V_{s}\left[\mathrm{~cm}^{3} \mathrm{~mol}^{-1}\right]$ is molar volume of solute; $a\left[\left(\mathrm{~cm}^{3}\right)^{b+1}(\mathrm{~kg} \mathrm{~J})^{-b}\right]$ and $b$ are fitting parameters; $R\left[8.314 \times 10^{-3} \mathrm{~kJ}\right.$ $\left.(\mathrm{mol} \mathrm{K})^{-1}\right]$ is the universal gas constant, $T[\mathrm{~K}]$ is the absolute temperature, $C_{s}\left[\mathrm{mg} \mathrm{L}^{-1}\right]$ is aqueous water solubility and $C_{e}\left[\mathrm{mg} \mathrm{L}^{-1}\right]$ is equilibrium solution concentration.

The PMM is widely employed for adsorption surfaces with heterogeneous energy distribution. The surface of CNTs generally consists of two energy states of carbon (i.e., graphite-like and disordered carbons) [36]. The PMM theory was developed to describe physical adsorption to microporous adsorbents. It involves a pore filling mechanism and the concept of a variable adsorption potential in response to pore filling. This theory would appear to be applicable in this case since MWCNTs form bundles in aqueous media and the spaces between the tubes within the bundles can be regarded as pores. Our data suggest that the PMM should be the recommended model for the adsorption of atrazine by MWCNTs as compared with other nonlinear models, such as Freundlich, Langmuir, dual-Langmuir and dual mode models [23,24].

The PMM fitting parameter of $Q^{0}$ (Table 3 ) and $q_{e \text {, measured }}$ (Table 2) indicated that the adsorption capacities of three MWCNTs followed a descending order: MWCNTs-O (0.85\%) > MWCNTs-O $(2.16 \%)>$ MWCNTs-O (7.07\%). This suggests that the adsorption capacity decreased when the surface oxygen contents of the MWCNTs increased. The mechanism responsible for this was ascribed to a more negatively charged MWCNT surface due to deprotonation of carboxylic groups at the equilibrium solution $\mathrm{pH}$ 6. At this $\mathrm{pH}$ the adsorption of water is more energetically favorable relative to the sorption of atrazine.

\subsection{Thermodynamic analysis}

The effect of temperature on the sorption of atrazine is shown in Fig. 6. An increase in temperature resulted in a corresponding decrease in the sorption of atrazine. This observation indicates that the uptake of atrazine on CNTs is an exothermic process. The standard free energy change, $\Delta G^{0}$, was evaluated using the following equation:

$\Delta G^{0}=-R T \ln K_{0}$

where $R\left[8.314 \mathrm{~J} \mathrm{~K}^{-1} \mathrm{~mol}^{-1}\right]$ is the universal gas constant and $T$ is the temperature in Kelvin. $K_{0}$ can be evaluated using a method described by Niwas et al. [37]:

$K_{0}=\frac{a_{s}}{a_{e}}=\frac{v_{s} C_{s}}{v_{e} C_{e}}$

where $a_{s}$ and $a_{e}$ are the activities of the adsorbed solute and the solute in solution at equilibrium, respectively, while $v_{s}$ and $v_{e}$ represent the activity coefficients of the adsorbed solute and the solute present in solution, $C_{s}\left[\mathrm{mg} \mathrm{g}^{-1}\right]$ and $C_{e}\left[\mathrm{mg} \mathrm{g}^{-1}\right]$ is the amount of atrazine adsorbed and atrazine in solution at equilibrium, respectively. When the concentration of the solute in solution approaches zero, the activity coefficient will approach unity and subsequently
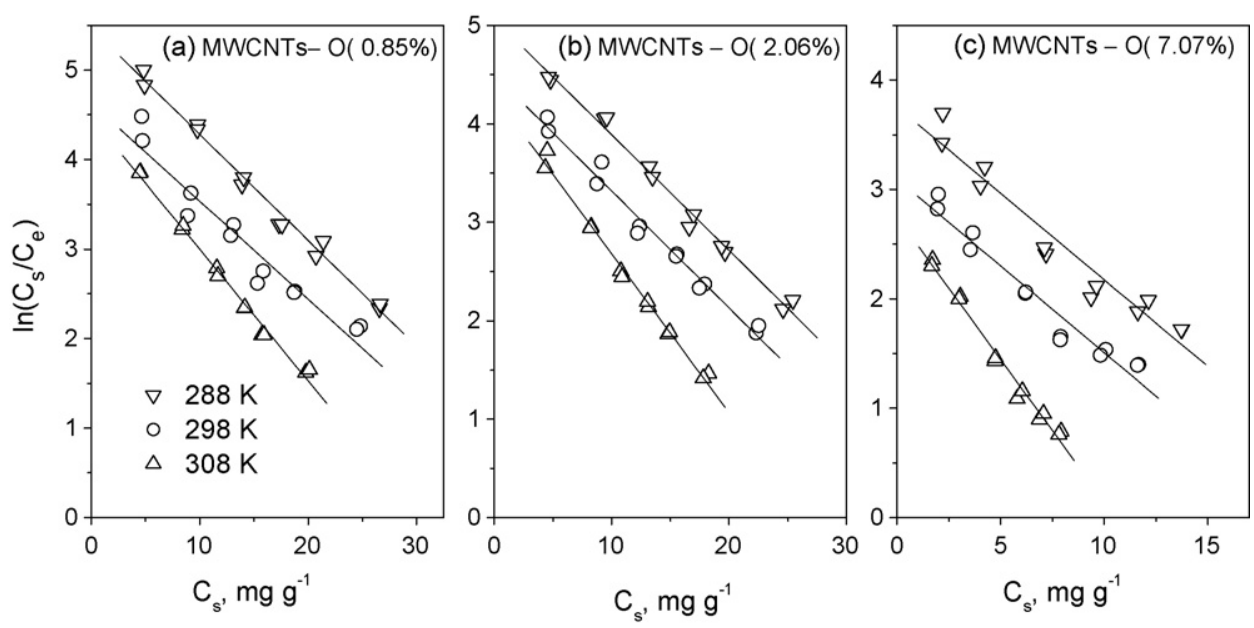

Fig. 6. Plots of $\ln q_{e} / C_{e}$ versus $q_{e}$ at various temperatures with ion strength of $0.01 \mathrm{M} \mathrm{NaNO}_{3}$. 
Table 3

Results of PMM fit to adsorption isotherms of atrazine on MWCNTs at $298 \mathrm{~K}$.

\begin{tabular}{|c|c|c|c|c|c|c|}
\hline & I.S. & $Q^{0}$ & $a$ & $b$ & $R^{2}$ & MWSE \\
\hline \multirow[t]{2}{*}{ MWCNTs-O (0.85\%) } & 0.01 & $61.10 \pm 15.94$ & $-25.95 \pm 9.56$ & $0.94 \pm 0.18$ & 0.9944 & 0.003 \\
\hline & 0.1 & $60.31 \pm 14.46$ & $-29.89 \pm 11.14$ & $1.00 \pm 0.18$ & 0.9944 & 0.06 \\
\hline \multirow[t]{2}{*}{ MWCNTs-O (2.16\%) } & 0.01 & $36.62 \pm 3.30$ & $-89.69 \pm 42.10$ & $1.48 \pm 0.19$ & 0.9944 & 0.003 \\
\hline & 0.1 & $33.28 \pm 3.30$ & $-108.65 \pm 54.41$ & $1.58 \pm 0.20$ & 0.9944 & 0.02 \\
\hline \multirow[t]{2}{*}{ MWCNTs-O (7.07\%) } & 0.01 & $25.62 \pm 9.73$ & $-110.34 \pm 30.14$ & $1.42 \pm 0.44$ & 0.9944 & 0.002 \\
\hline & 0.1 & $24.04 \pm 7.68$ & $-159.92 \pm 47.99$ & $1.56 \pm 0.45$ & 0.9944 & 0.002 \\
\hline
\end{tabular}

I.S. mean ionic strength; MWSE mean weighted square error, equal to $(1 / v) \sum\left(\left(q_{e, \text { measured }}-q_{e, \text { calculated }}\right) / q_{e, \text { measured }}\right)^{2}$, where $v$ is the amount of freedom, $v=n-3$.

Table 4

Thermodynamic parameters on the adsorption of atrazine by MWCNTs.

\begin{tabular}{|c|c|c|c|c|c|c|c|c|c|c|}
\hline \multirow[t]{2}{*}{ Carbons } & \multicolumn{3}{|l|}{$\ln K_{0}$} & \multicolumn{3}{|c|}{$\Delta G^{0}\left(\mathrm{~kJ} \mathrm{~mol}^{-1}\right)$} & \multirow[t]{2}{*}{$\Delta H^{0}\left(\mathrm{~kJ} \mathrm{~mol}{ }^{-1}\right)$} & \multicolumn{3}{|c|}{$\Delta S^{0}\left(\mathrm{~J} \mathrm{~mol}^{-1}\right)$} \\
\hline & $288 \mathrm{~K}$ & $298 \mathrm{~K}$ & $308 \mathrm{~K}$ & $288 \mathrm{~K}$ & $298 \mathrm{~K}$ & $308 \mathrm{~K}$ & & $288 \mathrm{~K}$ & $298 \mathrm{~K}$ & $308 \mathrm{~K}$ \\
\hline MWCNTs-O (0.85\%) & 5.47 & 4.9 & 4.47 & -13.1 & -12.14 & -11.45 & -36.87 & -82.56 & -85.88 & -88.29 \\
\hline MWCNTs-O (2.16\%) & 5.07 & 4.63 & 4.3 & -12.14 & -11.47 & -11.01 & -28.39 & -56.44 & -58.76 & -60.35 \\
\hline MWCNTs-O (7.07\%) & 3.76 & 3.1 & 2.75 & -9 & -7.68 & -7.04 & -37.24 & -98.06 & -102.65 & -104.86 \\
\hline
\end{tabular}

$K_{0}$ can be evaluated by plotting $\ln \left(C_{S} / C_{e}\right)$ against $C_{S}$ and extrapolating to zero (Fig. 6). Subsequently, the intercept with the $Y$-axis gives the value of $\ln K_{0}$.

The average standard enthalpy change $\left(\Delta H^{0}\right)$ is obtained from Van't Hoof equation:

$\ln K_{0}\left(T_{3}\right)-\ln K_{0}\left(T_{1}\right)=\frac{-\Delta H^{0}}{R}\left(\frac{1}{T_{3}}-\frac{1}{T_{1}}\right)$

where $T_{3}$ and $T_{1}$ are two different temperatures. The standard entropy change $\left(\Delta S^{0}\right)$ can be obtained by

$\Delta S^{0}=\frac{\Delta G^{0}-\Delta H^{0}}{T}$

The thermodynamic parameters are listed in Table 4 . The $\Delta G^{0}$ values were negative for atrazine at all three temperatures thereby implying that the adsorption of atrazine by MWCNTs was spontaneous and thermodynamically favorable. The observed negative $\Delta H^{0}$ suggested an exothermic sorption, which was supported by the observation that sorption of atrazine onto MWCNTs decreased with increase in temperature (Fig. 6). All the $\Delta H^{0}$ values, -36.87 , -28.39 , and $-37.24 \mathrm{~kJ} \mathrm{~mol}^{-1}$, were less than $40 \mathrm{~kJ} \mathrm{~mol}^{-1}$ thereby implying that the sorption of atrazine onto MWCNTs is mainly a physisorption process [38,39]. The negative $\Delta S^{0}$ indicated decreased randomness at the solid-liquid interface during sorption of atrazine. Furthermore, a more negative $\Delta G^{0}$ implied a greater driving force of sorption, resulting in a higher sorption capacity. When the oxygen content of MWCNTs increased from $0.85 \%$ to $7.07 \%, \Delta G^{0}$ became less negative. This suggests that the functional groups of MWCNTs caused the adsorption to become more difficult, i.e., the functional groups decreased the sorption affinity of MWCNTs for atrazine (Tables 2 and 3).

\section{Conclusion}

The adsorption of atrazine on three MWCNTs with different surface oxygen contents was studied using a batch technique. The adsorption isotherms of atrazine on MWCNTs were well described by PMM. The experimental results and fitting parameter of $Q^{0}$ indicated that the adsorption affinity decreased when the surface oxygen content increased despite similar outer diameter, surface area, mesoporosity and microporosity (Table 1 ). The calculated thermodynamic parameters indicated that adsorption of atrazine on MWCNTs was exothermic and spontaneous. $\Delta G^{0}$ became less negative when the oxygen content of MWCNTs increased from $0.85 \%$ to $7.07 \%$, thereby indicating that the sorption affinity of MWCNTs for atrazine was decreased. The high adsorption capacity of
MWCNTs implies that MWCNTs are a promising potential adsorbent for wastewater treatment. It has been reported that CNTs functionalized with hydrophilic $-\mathrm{OH}$ and $-\mathrm{COOH}$ groups exhibited superior sorption for low molecular weight and polar compounds [18]. It has been also proposed that functionalized MWCNTs may provide an optimized approach for removal of target specific micropollutants [40]. However, our results revealed that the introduction of oxygencontaining functional groups decreased the adsorption capacity of MWCNTs for atrazine. Obviously, more studies for the removal of other organic pollutants by functionalized MWCNTs are warranted.

\section{Acknowledgment}

This work was funded by the National Natural Science Foundation of China (grant number: 20707037).

\section{References}

[1] M. Streat, L.A. Sweetland, Removal of pesticides from water using hypercrosslinked polymer phases. Part 2-sorption studies, Trans. IChemE B 76(1998) 127-134.

[2] W.E. Pereira, C.E. Rostad, Occurrence, distributions and transport of herbicides and their degradation products in the lower Mississippi River and its tributaries, Environ. Sci. Technol. 24 (1990) 1400-1406.

[3] D.W. Koplin, S.J. Kalkhoff, D.A. Goolsby, D.A. Sneck-Fahrer, E.M. Thurman, Occurrence of selected herbicides and herbicide degradation products in Iowa's ground water, Ground Water 35 (1997) 679-688.

[4] M.D. Alvarez, L.A. Fuiman, Environmental levels of atrazine and its degradation products impair survival skills and growth of red drum larvae, Aquat. Toxicol. 74 (2005) 229-241.

[5] D. Zeljezic, V. Garaj-Vrhovac, P. Perkovic, Evaluation of DNA damage induced by atrazine and atrazine-based herbicide in human lymphocytes in vitro using a comet and DNA diffusion assay, Toxicol. In Vitro 20 (2006) 923-935.

[6] J.B. Sass, A. Colangelo, European union bans atrazine, while the United States negotiates continued use, Int. J. Occup. Environ. Health 12 (2006) 260-267.

[7] State Environmental Protection Administration of China, Environmental quality standard for surface water, China. GB3838-2002, China Environmental Science Publishing House, Beijing, 2002.

[8] M.O. Islan, M. Hara, J. Miyake, Induction of P-glycoprotein, glutathione-Stransferase and cytochrome P450 in rat liver by atrazine, Environ. Toxicol. Pharmacol. 12 (2002) 1-6.

[9] M.S. Christin, L. Menard, A.D. Gendron, S. Ruby, D. Cyr, D.J. Marcogliese, L. Rollins-Smith, M. Fournier, Effects of agricultural pesticides on the immune system of Xenopus laevis and Rana pipiens, Aquat. Toxicol. 67 (2004) 33-43.

[10] D.S. Gamble, Atrazine sorption kinetics in a characterized soil: predictive calculations, Environ. Sci. Technol. 42 (2008) 1537-1541.

[11] P. Chingombe, B. Saha, R.J. Wakeman, Sorption of atrazine on conventional and surface modified activated carbons, J. Colloid Interf. Sci. 302 (2006) 408-416.

[12] D.A. Laird, P.Y. Yen, W.C. Koskinen, T.R. Steinheimer, R.H. Dowdy, Sorption of atrazine on clay components, Environ. Sci. Technol. 28 (1994) 1054-1061.

[13] M.S. Mauter, M. Elimelech, Environmental applications of carbon-based nanomaterials, Environ. Sci. Technol. 42 (2008) 5843-5859.

[14] B. Fugetsu, S. Satoh, T. Shiba, T. Mizutani, Y. Lin, N. Terui, Y. Nodasaka, K. Sasa, K. Shimizu, T. Akasaka, Caged multiwalled carbon nanotubes as the adsorbents 
for affinity-based elimination of ionic dyes, Environ. Sci. Technol. 38 (2004) 6890-6896.

[15] R.Q. Long, R.T. Yang, Carbon nanotubes as superior sorbent for dioxin removal, J. Am. Chem. Soc. 123 (2001) 2058-2059.

[16] X. Peng, Y. Li, Z. Luan, Z. Di, H. Wang, B. Tian, Z. Jia, Adsorption of 1,2dichlorobenzene from water to carbon nanotubes, Chem. Phys. Lett. 376 (2003) 154-158.

[17] C. Lu, Y.L. Chung, K.F. Chang, Adsorption of trihalomethanes from water with carbon nanotubes, Water Res. 39 (2005) 1183-1189.

[18] K. Yang, L. Zhu, B. Xing, Adsorption of polycyclic aromatic hydrocarbons by carbon nanomaterials, Environ. Sci. Technol. 40 (2006) 1855-1861.

[19] C.J.M. Chin, L.C. Shih, H.J. Tsai, T.K. Liu, Adsorption of $o$-xylene and $p$-xylene from water by SWCNTs, Carbon 45 (2007) 1254-1260.

[20] C. Wu, Adsorption of reactive dye onto carbon nanotubes: equilibrium, kinetics and thermodynamics, J. Hazard. Mater. 144 (2007) 93-100.

[21] W. Chen, L. Duan, D. Zhu, Adsorption of polar and nonpolar organic chemicals to carbon nanotubes, Environ. Sci. Technol. 41 (2007) 8295-8300.

[22] B. Pan, D. Lin, H. Mashayekhi, B. Xing, Adsorption and hysteresis of bisphenol A and $17 \alpha$-ethynyl estradiol on carbon nanomaterials, Environ. Sci. Technol. 42 (2008) 5480-5485.

[23] X. Yan, B. Shi, J. Lu, C. Feng, D. Wang, H. Tang, Adsorption and desorption of atrazine on carbon nanotubes, J. Colloid Interf. Sci. 321 (2008) 30-38.

[24] G.C. Chen, X. Shan, Y. Wang, Z. Pei, X. Shen, B. Wen, G. Owens, Effects of copper, lead, and cadmium on the sorption and desorption of atrazine onto and from carbon nanotubes, Environ. Sci. Technol. 42 (2008) 8297-8302.

[25] I.D. Kovaios, C.A. Paraskeva, P.G. Koutsoukos, A.C. Payatakes, Adsorption of atrazine on soils: model study, J. Colloid Interf. Sci. 299 (2006) 88-94.

[26] W. Wu, S. Zhang, Y. Li, J. Li, L. Liu, Y. Oin, Z.X. Guo, L.M. Dai, C. Ye, D.B. Zhu, PVKmodified single-walled carbon nanotubes with effective photoinduced electron transfer, Macromolecules 36 (2003) 6286-6288.

[27] Y.S. Park, Y.C. Choi, K.S. Kim, D.C. Chung, D.J. Bae, K.H. An, S.C. Lim, X.Y. Zhu, Y.H. Lee, High yield purification of multiwalled carbon nanotubes by selective oxidation during thermal annealing, Carbon 39 (2001) 655-661.
[28] C. Lu, H. Chiu, Adsorption of zinc (II) from water with purified carbon nanotubes, Chem. Eng. Sci. 61 (2006) 1138-1145.

[29] F. Rouquerol, J. Rouquerol, K. Sing, Adsorption by Powders and Porous Material, Academic Press, San Diego, 1999.

[30] Y.S. Ho, G. McKay, Sorption of dye from aqueous solution by pit, Chem. Eng. J 70 (1998) 115-124.

[31] B. Benguella, H. Benaissa, Cadmium removal from aqueous solutions by chitin kinetic and equilibrium studies, Water Res. 36 (2002) 2463-2474.

[32] E. Guibal, P. McCarrick, J.M. Tobin, Comparison of the sorption of anionic dyes on activated carbon and chitosan derivatives from dilute solutions, Sep. Sci. Technol. 38 (2003) 3049-3073.

[33] N. Kannan, M. Meenakshýsundaram, Adsorption of Congo red on various activated carbons, Water Air Soil Pollut. 138 (2002) 289-305.

[34] A. Ozcan, A.S. Ozcan, Adsorption of acid red 57 from aqueous solutions onto surfactant-modified sepiolite, J. Hazard. Mater. 125 (2005) 252-259.

[35] K. Kannan, M.M. Sundaram, Kinetics and mechanism of removal of Methylene Blue by adsorption on various carbons-a comparative study, Dyes Pigments 51 (2001) 25-40.

[36] X. Liu, X. Lu, Q. Hou, Z. Lu, K. Yang, R. Wang, S. Xu, A new integrated method for characterizing surface energy heterogeneity from a single adsorption isotherm, J. Phys. Chem. B 109 (2005) 15828-15834.

[37] R. Niwas, U. Gupta, A.A. Khan, K.G. Varshney, The adsorption of phosphamidon on the surface of styrene supported zirconium (IV) tungstophosphate: a thermodynamic study, Colloids Surf. A 164 (2000) 115-119.

[38] M. Kara, H. Yuzer, E. Sabah, M.S. Celik, Adsorption of cobalt from aqueous solutions onto sepiolite, Water Res. 37 (2003) 224-232.

[39] B. von Oepen, W. Kordel, W. Klein, Sorption of nonpolar and polar compounds to soils: processes, measurements and experience with the applicability of the modified OECD-Guideline 106, Chemosphere 22 (1991) 285-304.

[40] H. Yan, A.J. Gong, H.S. He, J. Zhou, Y.X. Wei, L. Lv, Adsorption of microcystins by carbon nanotubes, Chemosphere 62 (2006) 142-148. 